KOŚCIÓŁ I PRAWO 10(23) 2021, nr 1, s. 45-55

DOI: http://dx.doi.org/10.18290/kip21101-3

Ginter Dzierżon

\title{
FUNKCJONOWANIE \\ KANONICZNEGO PORZĄDKU PRAWNEGO. PRAWO BOŻE, PRAWO LUDZKIE, PRAWO CZYSTO KOŚCIELNE W PRAWIE KANONICZNYM
}

\section{WPROWADZENIE}

W periodyku „Daimon” poświęconemu prawu komparatystycznemu religii opublikowano artykuł autorstwa A. Huxley'a pod prowokującym tytułem „Czy można mówić o religijnych systemach prawnych?” (Si può parlare di sistemi giuridici religiosi?) [Huxley 2001, 185-98]. W opracowaniu tym autor poddał $\mathrm{w}$ wątpliwość istnienie religijnych porządków prawnych. Uważam, iż taka teza jest daleka od istniejącej rzeczywistości, bo przecież de facto istnieją oraz funkcjonują takie porządki prawne, w tym również porządek kanoniczny Kościoła katolickiego. Przedmiotem mojej uwagi w tym opracowaniu stanie się system prawa kanonicznego, a bardziej szczegółowo mechanizmy jego funkcjonowania. Podejmując to niełatwe zagadnienie pragnę też spostrzec, że na międzynarodowym rynku wydawniczym istnieją pozycje, chociażby opublikowane drugie wydanie włoskiego dzieła zbiorowego „Sistemi giuridici nel mondo”, w którym nie poświęcono żadnej uwagi systemowi prawa Kościoła katolickiego [Crespi Reghizzi 2016].

Ks. PROF. DR HAB. GINTER DZIERŻON - Katedra Historii, Teorii i Norm Ogólnych Prawa Kanonicznego, Wydział Prawa Kanonicznego, Uniwersytet Kardynała Stefana Wyszyńskiego w Warszawie; adres do korespondencji: ul. Dewajtis 5, 01-815 Warszawa, Polska; e-mail: ginter.dzierzon@gmail.com; https://orcid.org/0000-0002-5116-959X 
Pragnę powtórzyć, iż nie ma wątpliwości co do tego, że taki porządek prawny istnieje i funkcjonuje. Cel jego funkcjonowania nie jest przyrodzony, ale nadprzyrodzony, o czym świadczy wieńczący Kodeks Prawa Kanonicznego z 1983 r. ${ }^{1}$ kan. 1752, w którym wyeksponowano w sposób szczególny pryncypialny cel prawa kościelnego, jakim jest zbawienie człowieka. Ten nadprzyrodzony cel wynika ze specyfiki tego porządku prawnego. Jak napisał V. De Paolis, źródła, z których Kościół korzysta w konstruowaniu systemu prawnego, to słowo Boże, magisterium Kościoła oraz normy Kościoła. Przy czym słowo Boże stanowi normę najwyższą [De Paolis 2010, 24].

$\mathrm{W}$ artykule tym zasygnalizowany problem zostanie ujęty $\mathrm{z}$ jednej perspektywy, to znaczy z aspektu poszczególnych obszarów prawa tworzących ten porządek. W skład jego struktury zatem wejdą trzy zasadnicze wątki tematyczne dotyczące: prawa Bożego, prawa ludzkiego oraz prawa czysto kościelnego. Rozważania zwieńczy namysł nad jeszcze jedną szczegółową, aczkolwiek ważką kwestią, jaką jest zobowiązanie wiernych do zachowania prawa.

\section{PRAWO BOŻE}

Fundamentem kanonicznego porządku prawnego jest prawo Boże. W tym kontekście rodzi się więc pytanie: co należy rozumieć pod tym pojęciem? Odpowiadając na to pytanie uczeni udzielają różnych odpowiedzi. Generalnie rzecz biorąc, idzie o prawo stworzone przez Boga [Filipponio 1998, 5]. Innymi słowy, idzie o porządek prawny, którego Bóg jest przyczyną sprawczą [tamże, 6]. W literaturze przedmiotu w odniesieniu do Boga Prawodawcy używa się różnych określeń, takich, jak chociażby Bóg jedyny, Bóg Trójosobowy, „Summum ens”, czy też „Summum bonum” [tamże, 5].

Rozważając problem prawa Bożego De Paolis stwierdził, że w tym przypadku idzie o prawo, w którym słowo Boże jest normą najwyższą nieuregulowaną, która reguluje wszystkie przejawy życia wspólnoty wiary. Norma

\footnotetext{
${ }^{1}$ Codex Iuris Canonici auctoritate Ioannis Pauli PP. II promulgatus (25.01.1983), AAS 75 (1983), pars II, s. 1-317; tekst polski: Kodeks Prawa Kanonicznego, przekład polski zatwierdzony przez Konferencję Episkopatu, Pallottinum, Poznań 1984 [dalej cyt.: KPK/83].
} 
ta jest aplikowana w każdym dniu życia wspólnoty wiernych jako doktryna, nauczanie, jak też jako praktyka życia [De Paolis 2010, 24]. Na poparcie tej tezy pragnę $\mathrm{w}$ tym miejscu przytoczyć pewne treści wyrażone przez papieża Jana Pawła II w konstytucji apostolskiej Sacrae disciplinae leges promulgującej obowiązującą kodyfikację. Otóż w dokumencie tym pytał On o walor kodeksu prawa kanonicznego? Udzielając na nie odpowiedzi stwierdził: „Aby właściwie odpowiedzieć na to pytanie, trzeba przypomnieć owo długie dziedzictwo prawa, które zawiera się w Księgach Starego i Nowego Testamentu i z którego cała tradycja prawna i prawodawcza Kościoła się wywodzi jakby ze swego pierwszego źródła"2. Komentując tę wypowiedź S. Berlingò podkreślił, że Pismo Święte jest pierwszym źródłem prawa kościelnego [Berlingò 1998, 55]. Prawda ta została obszernie m.in. ukazana w monografii „Gesù il Legislatore. Un contributo alla formazione del patrimonio storico-giuridico della Chiesa nel I millenio cristiano" napisanej przez O. Bucciego [Bucci 2011].

W doktrynie mówiąc o prawie Bożym rozróżnia się pomiędzy prawem Bożym naturalnym oraz prawem Bożym pozytywnym [Sobański 2001, 5768]. Generalnie rzecz ujmując, prawo Boże naturalne, to prawo wszczepione w naturę ludzką [Baura 2012, 165]. A.M. González określiła je jako pierwszą zasadę prawa (primero precepto de la ley) [González 2006, 73]. R. Sobański pisał zaś o normie podstawowej prawa kościelnego [Sobański 1992, 201-202]. Wyjaśniając tę kwestię K. Mörsdorf stwierdził, że prawo, o którym mowa, nie jest sztucznym tworem człowieka, ale świętym porządkiem stworzonym przez Boga [Mörsdorf 2008, 153].

Prawo Boże pozytywne natomiast, to prawo wiążące się, pomijając proces stworzenia, z wyraźną interwencją Boga. Na poparcie tej tezy przykładowo w publikacjach przywołuje się fakt powołania przez Chrystusa do życia Kościoła [Baura 2012, 165]. Ustawodawca promulgując to prawo przekazuje przez nie objawioną wolę Boga odnoszącą się do zachowań wiernych we wspólnocie Kościoła [Sobański 1992, 198]. Stąd też pierwotny rdzeń struktury Kościoła wypływa z tego obszaru [Gerosa 1998, 68]. Poruszając ten problem P. Lombardía skonstatował, że prawo Boże pozytywne jest prawem fundamentalnym Kościoła [Lombardía 2004, 69]. W niektórych normach kodeksowych znajdujemy wyraźne odniesienie do tej

\footnotetext{
${ }^{2}$ Ioannes Paulus PP. II, Constitutio apostolica Sacrae disciplinae leges (25.01. 1983), w: Kodeks Prawa Kanonicznego, przekład polski zatwierdzony przez Konferencję Episkopatu, Pallottinum, Poznań 1984, s. 11.
} 
postaci prawa Bożego. Przykładem może być kan. $207 \S 1 \mathrm{KPK} / 83$, zgodnie z którym „Z ustanowienia Bożego są w Kościele stany [...]” [Martín de Agar 2002, 32].

W Kościele prawo Boże spełnia dwie funkcje. Po pierwsze stanowi fundament porządku prawnego, pełniąc rolę konstytucyjną. Po drugie określa granice interpretacji oraz aplikacji prawa kanonicznego [García Gárate 2010, 203]. Pierwszy z wymiarów wyraża się w Tajemnicy Kościoła, która stanowi jego strukturę fundamentalną [Molano 2010, 227-28], drugi wymiar natomiast wynika $\mathrm{z}$ negatywnego odniesienia do prawa Bożego oraz jego norm. Precyzyjnie idzie o to, że są one nieprzekraczalną granicą dla stanowienia prawa ludzkiego [Lo Castro 1998, 70]. Ta zasada znajduje przełożenie w pryncypium, określonym m.in. w kan. $22 \mathrm{KPK} / 83$, w myśl którego normy ludzkie nie mogą być przeciwne prawu Bożemu [Miñambres 2010, 509]. Do kwestii tej odniósł się J. Miñambres w artykule „Il diritto divino come limite al rinvio normativo nell'ordinamento canonico" podkreślając, że każda regulacja funkcjonująca w systemie winna odnosić się do prawa Bożego. Dlatego tė̇ norma przeciwna prawu Bożemu jest niesprawiedliwa (ingiusta), gdyż występuje w niej brak elementu istotnego [tamże, 507].

W analizie prezentowanego problemu nie można pominąć jeszcze jednego wątku związanego $\mathrm{z}$ niezmiennością prawa Bożego. $\mathrm{Z}$ tego względu, że Bóg jest niezmienny, to również prawo Boże jest niezmienne. Należy jednak spostrzec, iż prawo Boże jest bez wątpienia niezmienne, ale posiada też wymiar historyczny, ponieważ jest prawem w ciągu dziejów adresowanym do ludzkości. Celnie spostrzegł Sobański: „Niezmienność nie dotyczy sformułowania owego prawa [...], lecz treści, czyli materialnego substratu ogłoszonego prawa Bożego" [Sobański 2001, 72-76]. Jego promulgacja w pryzmacie historycznym dokonuje się poprzez przepowiadanie.

\section{PRAWO BOŻE A PRAWO LUDZKIE}

Jak już zasygnalizowano, prawo Boże występuje zawsze w historycznej postaci, a więc $\mathrm{w}$ formie prawa ludzkiego. W jego skład wchodzą $\mathrm{z}$ jednej strony normy, które są wywiedzione z Bożego objawienia, z drugiej zaś komponent ludzki wiążący się z możliwościami poznawczymi człowieka [Tenże 1992, 90]. Celnie zauważyła A. Filipponio, że porządek prawny 
ustanowiony przez Boga jest jednym ze środków komunikacji pomiędzy Nim a człowiekiem [Filipponio 1998, 15]. Prawo Boże, jak napisał E. Molano, domaga się mediacji ludzkiej [Molano 2010, 229]. Na związku bowiem pomiędzy normatywnością prawa Bożego oraz ludzkim wymiarem ontologiczno-przyczynowym opiera się funkcjonowanie Kościoła [Kistner 2009, 147]. Norma Boża z tej racji, że jest wpisana w naturę ludzką, jest zgodna z ludzkimi zdolnościami percepcyjnymi. Człowiek jest zdolny do tego, aby ją opisać i rozpowszechnić [Salvatori 2001]. Według Sobańskiego ujęcie prawa Bożego w normę jest efektem dwóch czynników: stanu ludzkiej wiedzy w konkretnym czasie oraz interpretacji. Rozwijając tę myśl zwrócił uwagę, iż w kanonicznym porządku prawnym nie wszystkie regulacje wynikają wprost z Bożego Objawienia. W swym namyśle nad tym zagadnieniem wyróżnił on: normy dotyczące prawd objawionych uznane przez Kościół jako nieomylne, normy określające treści wynikające bezpośrednio z Objawienia Bożego oraz wskazania wyrażone w formie normatywnej wydedukowane na zasadzie wnioskowania z Objawienia Bożego [Sobański 2001, 69]. Przy tym należy zauważyć, iż w doktrynie rozróżnia się jeszcze pomiędzy prawem Bożym pierwszorzędnym i prawem Bożym drugorzędnym. W pierwszym przypadku idzie o pryncypia właściwe jemu. W drugim wypadku chodzi o konsekwencje prawne wirtualnie wypływające $\mathrm{z}$ niego [Molano 2010, 227-28].

W związku z takim stanem doktrynalnym rodzi się pytanie: o pozycję najwyższego ustawodawcy kościelnego w odniesieniu do prawa Bożego pozytywnego? Wyjaśniając tę kwestię Sobański napisał: „Jego rola odnośnie prawa Bożego nie polega na nadaniu mu prawnego charakteru, lecz na jego operatywnym sformułowaniu oraz historycznej konkretyzacji, na «opracowaniu» prawa Bożego za pomocą metod i technik osiągalnych na danym etapie kultury prawnej" [Sobański 2001, 81-82]. Według przedstawiciela dogmatycznej szkoły prawa kanonicznego V. Del Giuidce kanoniczny porządek prawny jest wprawdzie efektem aktywności ludzkiej, ale prawo Boże jest obecne w Kościele dzięki recepcji formalnej przez prawodawcę [Baura 2012, 166]. Dlatego też prawotwórczy wysiłek ustawodawcy kościelnego polega nie na jego konstruowaniu, ale na jego deklaracji. 


\section{PRAWO CZYSTO KOŚCIELNE}

W doktrynie mówi się jeszcze o jednym rodzaju prawa, jakim jest prawo czysto kościelne. W tym wypadku idzie o ludzkie prawo pozytywne [Heinzmann 2012, 97; Martín de Agar 2002, 32]. Podejmując ten problem na wstępie należy podkreślić z całym naciskiem, iż wszystkie obszary prawa, o których dotychczas była mowa, są w jakimś sensie prawem kościelnym. Występujący w zwrocie podtytułu przysłówek „czysto” (mere) wprowadzono do obrotu normatywnego w celu odróżnienia prawa pozytywnego od prawa Bożego i prawa ludzkiego. Źródłem bowiem tego prawa jest władza ludzka [Heinzmann 2012, 97]. W sensie negatywnym pod tę kategorię nie podpadają normy deklarujące prawo Boże [Tenże 2002, 61]. Wyjaśniając ten problem Sobański napisał: „Prawo Boże i prawo stanowione przez Kościół trzeba rozróżnić, ale nie należy jednego od drugiego odłączać: prawo Boże ogłasza się w otoczce prawa kościelnego, zaś prawo (czysto) kościelne wiąże się z prawem Bożym i w nim tylko się uzasadnia” [Sobański 2001, 70].

Poruszając kwestię konceptu ustawodawstwa kościelnego należy jeszcze zwrócić uwagę, że w kanonistyce rozróżnia się pomiędzy jego wymiarem zewnętrznym i wymiarem wewnętrznym. Pierwszy z nich związany jest ze społecznym charakterem sprawowania władzy. Tym, co charakteryzuje ten obszar to publiczny charakter oraz udawadnialność [Dzierżon 2018, 184]. W. Aymans ukazując problem wymiaru zewnętrznego nawiązał do kan. $29 \mathrm{KPK} / 83$ dotyczącego dekretów ogólnych, ponieważ - jego zdaniem - w nim wyraża się istota prawotwórstwa. Otóż w kanonie tym stwierdzono, że akty wydawane na forum zewnętrznym przez kompetentną władzę są przeznaczone dla wspólnoty zdolnej do przyjęcia ustawy [Aymans 1985, 465]. Sfera wewnętrzna natomiast dotyczy aktów podejmowanych $\mathrm{w}$ sposób tajny. W doktrynie wskazuje się, iż w tym wypadku sprawowanie może mieć charakter sakramentalny lub pozasakramentalny. Należy jednak zauważyć, iż działania podejmowane w tym obszarze nie wiążą się z działalnością prawotwórczą. Dotyczą spraw wiernych odnoszących się do dobra prywatnego. $\mathrm{Z}$ reguły nie można ich udowodnić w zakresie zewnętrznym [Dzierżon 2018, 184-85].

Omawiając problem prawa czysto kościelnego nie można pominąć kolejnego wątku, mianowicie $\mathrm{w}$ systemie tym waloru prawa pozytywnego kościelnego nie można utożsamiać $\mathrm{z}$ walorem norm prawa świeckiego, gdyż pomiędzy Kościołem a rzeczywistością świecką istnieją pewne różnice. 
Otóż Kościół w przeciwieństwie do państwa nie powstał z woli ogółu, ale z woli Boga. Poza tym Kościół w odróżnieniu od wspólnoty świeckiej jest wspólnotą wiary. Władza kościelna więc nie może stanowić prawa, które byłoby sprzeczne z prawem Bożym [Heinzmann 2002, 46]. Na poparcie tej tezy należy przywołać jeszcze raz wywód Sobańskiego, w którym utrzymywał: „Trudność ścisłego rozgraniczenia wynika nie tyle z niedostatków poznawczych, ale z «natury rzeczy». Przy założeniu, że Kościół stanowi prawo wierny swojej misji i w ciągłym nasłuchu na wolę Pana, relatywizuje się pytanie, czy odnośna instytucja lub norma wynika z Objawienia wprost lub tylko pośrednio i jak daleko sięga ludzki wkład w jej kształtowanie. Rzecz w tym, by całe prawo Kościoła harmonizowało z misją powierzoną mu przez Chrystusa. Tę wynikającą z Bożej woli zbawczej misję Kościół ma na uwadze, zarówno wtedy, gdy jest przekonany, że proklamuje prawo Boże, jak też wówczas, gdy dla jego realizacji otacza je prawem przez siebie stanowionym" [Sobański 2001, 71].

\section{ZOBOWIĄZANIE WIERNYCH DO ZACHOWANIA PRAWA}

Poruszając problem zobowiązania wiernych do zachowania prawa najpierw należałoby przywołać kan. $11 \mathrm{KPK} / 83$, w myśl którego „Ustawom czysto kościelnym podlegają ochrzczeni w Kościele katolickim lub do niego przyjęci, którzy jednak posiadają wystarczające używanie rozumu oraz - jeśli ustawa czego innego wyraźnie nie zastrzega - ukończyły siódmy rok życia”.

Mając na uwadze zasadniczy cel tego artykułu trzeba stwierdzić, iż prawo stanowione w Kościele obowiązuje katolików, o czym świadczy normatywny zwrot „ochrzczeni w Kościele katolickim lub do niego przyjęci”. W tym kontekście sprawą kluczową staje się problem recepcji prawa przez wiernych. Do tego są oni zobligowani. Procesu recepcji jednak nie należy pojmować w kategoriach pozytywistycznych, ale jako przyjęcie pewnej formy przepowiadania. Stąd też wszystkie ustawy wiążą w sumieniu [Sobański 1992, 187] pozostając w ścisłym związku z fenomenem ludzkiej wiary. A. Derdziuk jeden ze swoich artykułów zatytułował nawet prowokacyjnie w formie pytania „Sumienie ponad prawem?” [Derdziuk 2006, 61-78].

Przy tym należy zauważyć, iż kan. $11 \mathrm{KPK} / 83$ nie dotyczy jednak wymogów wynikających $\mathrm{z}$ prawa naturalnego i prawa Bożego, do którego 
przestrzegania zobowiązani są wszyscy ludzie dysponujący odpowiednią zdatnością tak w sferze intelektualnej, jak i wolitywnej [De Paolis i D'Auria 2008, 126]. Prawdę tę odzwierciedla kan. $748 \S 1$ KPK/83: „Wszyscy ludzie są obowiązani szukać prawdy dotyczącej Boga i Jego Kościoła, a poznaną mają obowiązek i prawo z mocy Prawa Bożego przyjąć i zachowywać”. Przy tym trzeba zwrócić uwagę, iż deklaracja ta jednak nie pociąga żadnych konsekwencji względem akatolików [Sobański 2002, 85].

\section{ZAKOŃCZENIE}

$\mathrm{Z}$ rozważań zaprezentowanych $\mathrm{w}$ tym opracowaniu wynika, iż funkcjonowania kanonicznego porządku prawnego nie można postrzegać pozytywistycznie. Fundamentu tego systemu nie tworzy bowiem jedynie prawo ludzkie, ale prawo Boże. To ono w systemie pełni $\mathrm{z}$ jednej strony funkcję konstytutywną, z drugiej zaś wyznacza granice interpretacji oraz aplikacji prawa kanonicznego. U podstaw prawa kościelnego leżą pryncypia teologiczne.

Ontologicznie prawo to jest niezmienne, ponieważ jednym $\mathrm{z}$ atrybutów Boga jest niezmienność. Historycznie natomiast jest ono prawem adresowanym do ludzkości. Dlatego też, jak wykazano, niezmienność dotyczy substratu materialnego prawa, nie odnosi się natomiast do procesu sformułowania prawa. Stąd też prawo Boże jest deklarowane przez ustawodawcę kościelnego w konkretnym kontekście historycznym. Ze względu na swą zdolność percepcyjną człowiek jest zdolny to prawo opisać i rozpowszechnić. Toteż $\mathrm{w}$ konstruowaniu kościelnego systemu prawnego nie można abstrahować od czynnika ludzkiego.

Należy dodać, iż wyeksponowanie w opracowaniu poszczególnych warstw prawa kościelnego ma charakter teoretycznoprawny. Występowanie kategorii prawa czysto kościelnego służy przede wszystkim odróżnieniu tej postaci prawa od prawa Bożego i prawa ludzkiego. Prawo Boże zaś jest zwornikiem i wyznacznikiem wszelkich norm. Zgodnie z założeniami systemowymi władza kościelna nie może stanowić prawa, które byłoby sprzeczne z prawem Bożym. 


\section{PIŚMIENNICTWO}

Aymans, Winfried. 1985. „Lex canonica. Consideraciones sobre el concepto de ley canónica." Ius Canonicum 25, nr 2:463-78.

Baura, Eduardo. 2012. Parte generale del diritto canonico. Diritto e sistema normativo. Roma: EDUSC.

Berlingò, Salvatore. 1998. „La prospettiva canonistica: profili ontologico-normativi del diritto di una Chiesa." W Ius divinum. Fondamentalismo religioso ed esperienza giuridica, red. Francesco D’Agostino, 51-76. Torino: Giappichelli Editore.

Bucci, Onorato. 2011. Gesù il Legislatore. Un contributo alla formazione del patrimonio storico-giuridico della Chiesa nel I millenio cristiano. Città del Vaticano: Libreria Editrice Vaticana.

Crespi Reghizzi, Gabriele, red. 2016. Sistemi giuridici nel mondo. Wyd. 2. Torino: Giappichelli Editore.

De Paolis, Valesio, i Andrea D’Auria. 2008. Le norme generali di Diritto Canonico. Commento al Codice di Diritto Canonico. Roma: Urbaniana University Press.

De Paolis, Valesio. 2010. „Le fonti che la Chiesa riconosce come normative per sé.” W Javier Otaduy, Lezioni di diritto canonico. Tłum. Giuseppe Comotti, 24-25. Venezia: Marcianum Press.

Derdziuk, Andrzej. 2006. „Sumienie ponad prawem?” W Forum internum i forum internum $w$ prawie kanonicznym, red. Ambroży Skorupa, 61-78. Lublin: Wydawnictwo KUL.

Dzierżon, Ginter. 2018. „Zakresy sprawowania władzy rządzenia w kanonicznym porządku prawnym (kan. 130 Kodeksu Prawa Kanonicznego z 1983 roku).” Roczniki Nauk Prawnych 28, nr 3:181-91.

Filipponio, Angiola. 1998. „Normazione divina e normazione umana.” W Diritto divino e legislazione umana, red. Angiola Filipponio, i Raffaele Coppola, 3-18. Torino: Giappichelli Editore.

García Gárate, Alfredo. 2010. „Ius divinum» y Derecho Canónico.” W Ius divinum, red. Juan I. Arrieta, i Costantino M. Fabris, 195-203. Venezia: Marcianium Press.

Gerosa, Libero. 1998. Prawo Kościoła. Tłum. Ireneusz Pękalski. Poznań: Pallottinum.

González, Ana M. 2006. Claves de ley natural. Madrid: Ediciones Rialp, S.A.

Heinzmann, Marcelo C. 2002. Le leggi irritanti e inhabilitanti. Roma: Gregorian University Press.

Heinzmann, Marcelo C. 2012. „Ley meramente ecclesiástica.” W Diccionario general de Derecho Canónico, red. Javier Otaduy, Antonio Viana, i Joaquín Sedano, t. 5, 96-98. Pamplona: Thomson Reuters Arazandi.

Huxley, Andrew. 2001. „Si può parlare di sistemi giuridici religiosi?” Daimon 1:185-98.

Kistner, Peter. 2009. Das göttliches Recht und die Kirchenverfassung. Berlin: LIT Verlag.

Lo Castro, Gaetano. 1998. „Dimensione «umana» nel diritto divino.” W Diritto divino e legislazione umana, red. Angiola Filipponio, i Raffaele Coppola, 33-77. Torino: Giappichelli Editore.

Lombardía, Pedro. 2004. Lecciones de derecho canónico. Wyd. 2. Madrid: Tecnos. 
Martín de Agar, José T. 2002. Introducción al derecho canónico. Wyd. 2. Madrid: Tecnos.

Miñambres, Jesús. 2010. „Il diritto divino come limite al rinvio normativo nell'ordinamento canonico." W Ius divinum, red. Juan I. Arrieta, i Costantino M. Fabris, 501-12. Venezia: Marcianum Press.

Molano, Eduardo. 2010. „Derecho divino y derecho constitutional canónico.” W Ius divinum, red. Juan I. Arrieta, i Costantino M. Fabris, 223-37. Venezia: Marcianum Press.

Mörsdorf, Klaus. 2008. Fondamenti del diritto. Tłum. Stefano Testa Bappenheim. Venezia: Marcianum Press.

Salvatori, Davide. 2001. L'oggetto del magistero definitivo della Chiesa alla luce del m.p. Ad Tuendam Fidem: il can. 750 visto attraverso $i$ Concili Vaticani. Roma: Gregorian University Press.

Sobański, Remigiusz. 1992. Teoria prawa kościelnego. Warszawa: Wydawnictwo UKSW.

Sobański, Remigiusz. 2001. Nauki podstawowe prawa kanonicznego. Teologia prawa kościelnego. Warszawa: Wydawnictwo UKSW.

\section{Funkcjonowanie kanonicznego porządku prawnego. Prawo Boże, prawo ludzkie, prawo czysto kościelne w prawie kanonicznym}

\section{Streszczenie}

W zaprezentowanym opracowaniu Autor podjął namysł nad funkcjonowaniem kanonicznego porządku prawnego. Wykazał on, iż prawa kościelnego nie można postrzegać pozytywistycznie. Fundamentu tego systemu nie tworzy bowiem prawo ludzkie, ale prawo Boże. To ono w systemie pełni $\mathrm{z}$ jednej strony funkcję konstytucyjną, $\mathrm{z}$ drugiej zaś określa granice interpretacji oraz aplikacji prawa kanonicznego. U podstaw prawa kościelnego leżą pryncypia teologiczne.

Ontologicznie prawo Boże jest niezmienne, ponieważ jednym z atrybutów Boga jest niezmienność. Historycznie natomiast jest ono prawem adresowanym do ludzkości. Dlatego też niezmienność dotyczy substratu materialnego prawa, nie odnosi się do sformułowania prawa. Prawo Boże jest zatem deklarowane przez ustawodawcę kościelnego w konkretnym kontekście historycznym. Ze względu na swą zdolność percepcyjną człowiek jest zdolny je opisać i rozpowszechnić. W tworzeniu kościelnego systemu prawnego nie można więc abstrahować od czynnika ludzkiego.

Zdaniem Autora, wskazywanie w doktrynie na poszczególne warstwy systemu prawnego, jakimi są prawo Boże, prawo ludzkie, prawo czysto kościelne ma charakter teoretycznoprawny. Występowanie kategorii prawa czysto kościelnego służy przede wszystkim odróżnieniu tego prawa od prawa Bożego i prawa ludzkiego. Prawo Boże jest zwornikiem i wyznacznikiem wszelkich norm. Władza kościelna zatem nie może stanowić prawa, które byłoby sprzeczne z prawem Bożym.

Słowa kluczowe: kanoniczny porządek prawny; prawo Boże; prawo ludzkie; prawo czysto kościelne 


\section{The Functioning of the Canonical Legal Order. God's Law, Human Law, Solely Ecclesiastical Law in the Canonical Legal System}

\section{Summary}

The author of the article discusses the functioning of the canonical legal order. He proves that ecclesiastical law cannot be perceived positivistically since it is founded on God's law and not man-made law. It plays a constitutional role in this system but, on the other hand, sets boundaries to interpretation and application of canon law. The base for canon law is theological principles.

From the ontological perspective, God's law is invariable because permanence is one of the attributes of God. However, from the historical point of view, since this law is addressed to people, its invariability does not refer to the formulation of law but to the positive substratum of law. Therefore, God's law is declared by the ecclesiastical legislator in a specific historical context. Thanks to their perceptive capabilities, the person is able to describe this law and spread it. This proves that one cannot disregard the human factor in designing the ecclesiastical legal system.

In the author's opinion, indication in the doctrine of the different layers of the legal system, such as God's law, human law, and solely ecclesiastical law, is of a theoretical and legal nature. The purpose of using the category of solely ecclesiastical law is to differentiate it from God's law and man-made law. Still, God's law remains the keystone and foundation of all norms. The ecclesiastical power cannot therefore make any law which would stand against the law of God.

Keywords: canonical legal order; God's law; human law; solely ecclesiastical law

Information about Author: REv. PROF. DR. HABIL. GINTER DZIERŻON - Department of History, Theory and General Norms of Canon Law, Faculty of Canon Law, the Cardinal Stefan Wyszyński University in Warsaw; correspondence address: ul. Dewajtis 5, 01-815 Warszawa, Poland; e-mail: ginter.dzierzon@gmail.com; https:// orcid.org/0000-0002-5116-959X 